PPPL-3459

UC-70

Physics Results from the National Spherical Torus Experiment

by

M.G. Bell for the NSTX Research Team

June 2000

$\int \frac{D}{5}[\sqrt{\zeta}] \int \Omega \begin{aligned} & \text { PAINCETON } \\ & \text { PLABMA PHYSICS } \\ & \text { LABOAATOAY }\end{aligned}$

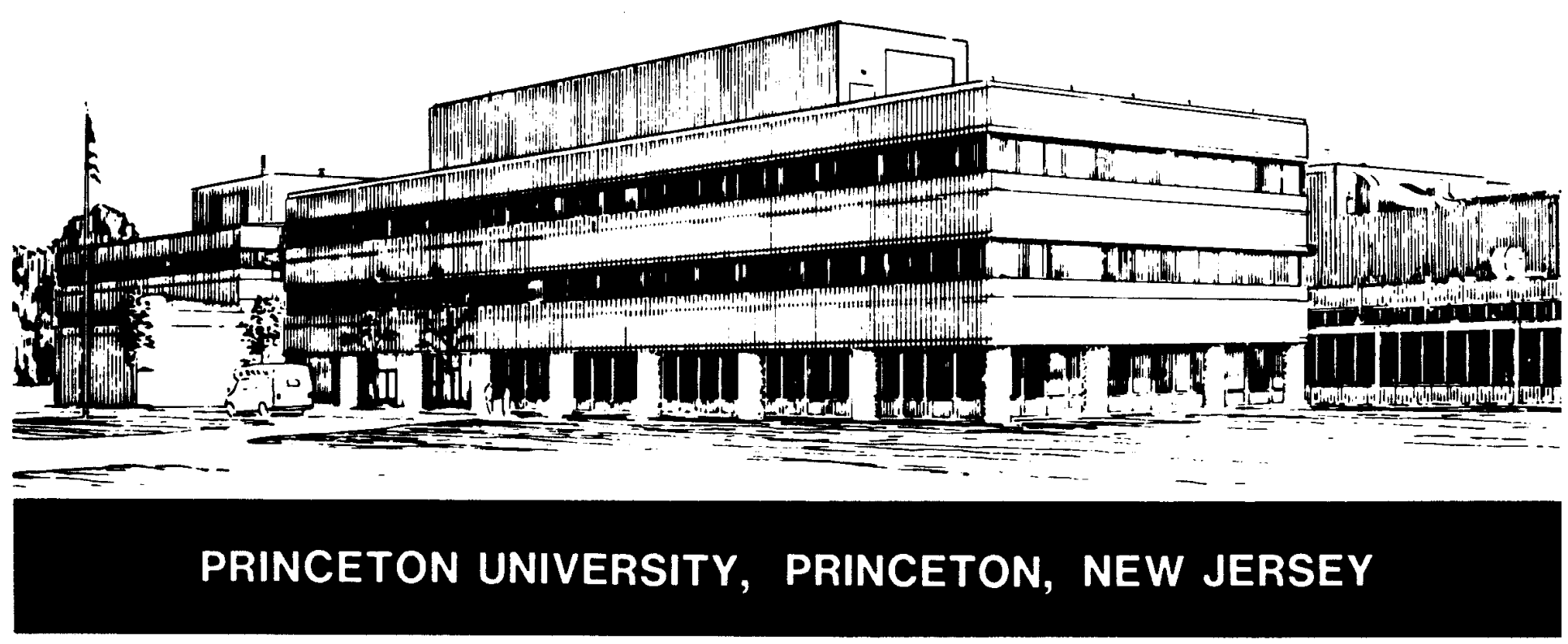




\section{PPPL Reports Disclaimer}

This report was prepared as an account of work sponsored by an agency of the United States Government. Neither the United States Government nor any agency thereof, nor any of their employees, makes any warranty, express or implied, or assumes any legal liability or responsibility for the accuracy, completeness, or usefulness of any information, apparatus, product, or process disclosed, or represents that its use would not infringe privately owned rights. Reference herein to any specific commercial product, process, or service by trade name, trademark, manufacturer, or otherwise, does not necessarily constitute or imply its endorsement, recommendation, or favoring by the United States Government or any agency thereof. The views and opinions of authors expressed herein do not necessarily state or reflect those of the United States Government or any agency thereof.

\section{Availability}

This report is posted on the U.S. Department of Energy's Princeton Plasma Physics Laboratory Publications and Reports web site in Calendar Year 2000. The home page for PPPL Reports and Publications is: http://www.pppl.gov/pub_report/

DOE and DOE Contractors can obtain copies of this report from:

U.S. Department of Energy

Office of Scientific and Technical Information

DOE Technical Information Services (DTIS)

P.O. Box 62

Oak Ridge, TN 37831

Telephone: (865) 576-8401

Fax: (865) 576-5728

Email: reports@adonis.osti.gov

This report is available to the general public from:

National Technical Information Service

U.S. Department of Commerce

5285 Port Royal Road

Springfield, VA 22161

Telephone: $1-800-553-6847$ or

(703) $605-6000$

Fax: (703) 321-8547

Internet: http://www.ntis.gov/ordering.htm 


\title{
Physics Results from the National Spherical Torus Experiment
}

\author{
M.G. Bell for the NSTX Research Team \\ Plasma Physics Laboratory, Princeton University, Princeton, NJ, 08543 U.S.A.
}

The National Spherical Torus Experiment (NSTX) at the Princeton Plasma Physics Laboratory is designed for studying toroidal plasma confinement at very low aspect-ratio, $\mathrm{A}=\mathrm{R} / \mathrm{a}=0.85 \mathrm{~m} / 0.68 \mathrm{~m} \sim 1.25$, with cross-section elongation up to 2.2 and triangularity up to 0.5 , for plasma currents up to $1 \mathrm{MA}$ and vacuum toroidal magnetic fields up to $0.6 \mathrm{~T}$ on axis. Conducting plates are installed close to the plasma on the outboard side to stabilize kink modes. This should permit operation with toroidal- $\beta$ approaching $40 \%$ [1]. The plasmas will be heated by up to $6 \mathrm{MW}$ High-Harmonic Fast Waves (HHFW) at a frequency $30 \mathrm{MHz}$ and by $5 \mathrm{MW}$ of $80 \mathrm{keV}$ deuterium Neutral Beam Injection. Inductive plasma startup can be supplemented by the process of Coaxial Helicity Injection (CHI).

The first operational phase from September 1999 to January 2000 concentrated on commissioning the control, heating and current-drive systems, developing the range of plasma configurations possible, measuring the poloidal flux consumption and characterizing the operational space. The first wall was prepared for plasma operation by a combination of bakeout $\left(300^{\circ} \mathrm{C}\right.$ on the center stack and $\sim 200^{\circ} \mathrm{C}$ on the stabilizer plate tiles) and glow-

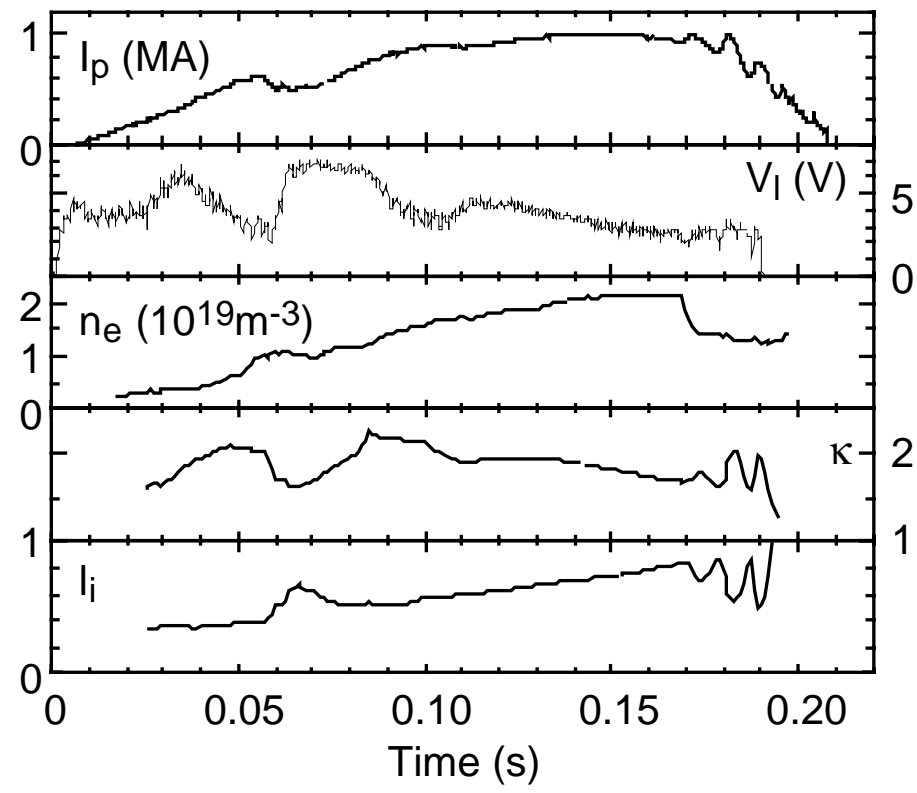

Fig. 1 Evolution of plasma current $\left(I_{p}\right)$, loop voltage $\left(V_{l}\right)$, line-average electron density $\left(n_{e}\right)$, elongation $(\kappa)$ and internal inductance $\left(l_{i}\right)$ for a 1 MA inductive discharge with aspect ratio 1.28. discharge conditioning, initially in deuterium (to remove residual hydrogen) and then in helium [2]. As shown in Fig. 1, low aspect-ratio plasmas with inductively driven currents up to $1 \mathrm{MA}$ have been achieved at a toroidal magnetic field of $0.3 \mathrm{~T}$ with quasi-steady elongations $1.5-2.0$ and triangularity up to 0.4 . Higher elongation, up to 2.2 , and triangularity, up to 0.6 , have been reached transiently. The plasma current is initiated in deuterium at a pressure of $8-12 \mathrm{mPa}$ by inducing a toroidal loop voltage of $3-4 \mathrm{~V}$. Breakdown may be assisted by applying a $10 \mathrm{~kW}, 20 \mathrm{~ms}$ pulse of $18 \mathrm{GHz} \mathrm{RF}$ power, resonant with the electron cyclotron frequency at a radius of $\sim 0.4 \mathrm{~m}$.

In this first phase, the gap between the plasma boundary and the first wall at the outboard midplane, the plasma vertical position and the plasma current were feedback controlled using digital signal processing to control the currents in two pairs of poloidal field coils and

"Including: S.A. Sabbagh (Columbia U.); M.J. Schaffer (GA); D. Stutman (JohnsHopkins U.); R. Maqueda, G.A. Wurden (LANL); R. Maingi, Y.M. Peng, D.W. Swain, J.B. Wilgen (ORNL); R.E. Bell, D.A. Gates, S.M. Kaye, E. Mazzucato, J. Menard, D. Mueller, M. Ono, J.R. Wilson (PPPL); T. Jarboe, B.A. Nelson, R. Raman (U. Washington) 
the central solenoid. The shape of the outer boundary was controlled by pre-programming the currents in other poloidal field coils. The equilibrium configuration is analyzed after each shot with the EFIT code [3] using the measured coil currents and data from up to 75 sensors which measure the poloidal flux and magnetic field components outside the plasma. Plasmas limited on the inboard side by carbon tiles, single-null (asymmetric) and double-null (symmetric) divertor plasma configurations have been produced as shown in Fig. 2. In addition to providing the shape of the boundary, the EFIT analysis yields the internal inductance parameter, $\mathrm{l}_{\mathrm{i}}$, and energy content. In future experiments, real-time analysis of the equilibrium and feedback control of many more discharge parameters will be implemented
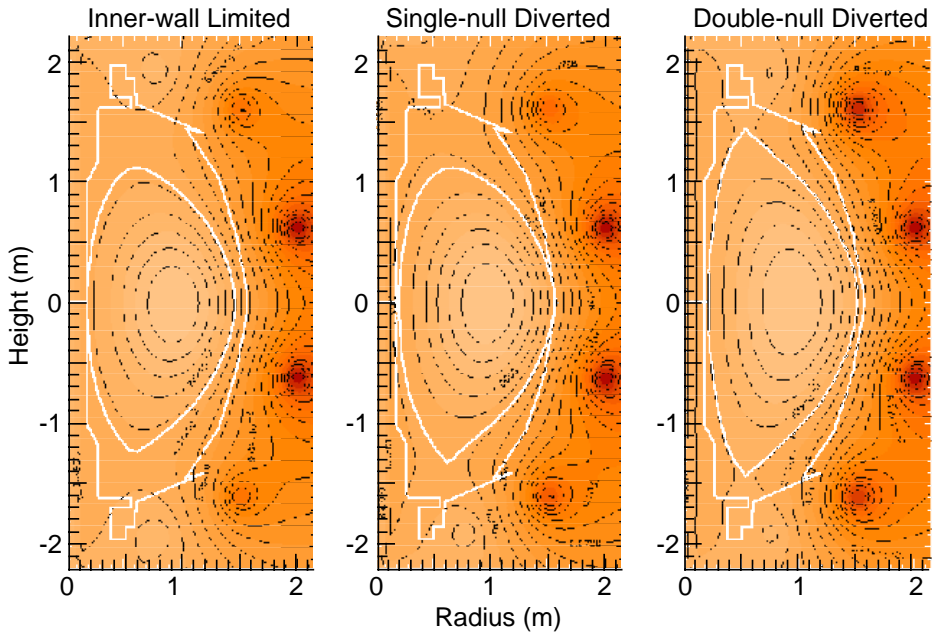

Fig. 2 Cross-sections from EFIT analysis of plasmas run in the three main equilibrium configurations in NSTX: a) inner wall limited; $b$ ) lower single-null divertor; c) double-null divertor [4].

The poloidal flux consumption during inductive startup was studied as a function of the plasma current and its rate of rise. For peak currents in the range $0.6-0.8 \mathrm{MA}$, the flux consumption was minimized by programming a rate of rise of $5-7 \mathrm{MA} / \mathrm{s}$. The Ejima coefficient, defined as the normalized resistive flux consumption to reach a given current $\mathrm{I}_{\mathrm{p}}, \mathrm{C}_{\mathrm{e}}=$ $\int V_{\text {res }} d t / \mu_{0} R_{p} I_{p}$, where $V_{\text {res }}$ is the resistive part of the loop voltage at the plasma surface and $R_{p}$ is the major radius of the magnetic axis, was as low as 0.35 , similar to values measured for conventional aspect ratio tokamaks [5].

A variety of MHD phenomena has been observed in the ohmically heated plasmas, including sawtooth oscillations, internal and global reconnections, kinks and disruptions. These are evident in the signals from magnetic pickup coils outside the plasma, from collimated soft x-ray detectors and from fast optical TV images of the plasma. During the current ramp, MHD instabilities frequently occurred and affected the plasma evolution, as seen for example in Fig. 1 at $0.045 \mathrm{~s}$. The increase in the internal inductance indicates rapid redistribution of the plasma current. Magnetic pickup coils showed the presence of rapidly growing perturbations which are believed to be double-tearing modes [6] occurring when the q-profile becomes double valued as a result of the rapid rise of the current initially. Higher current ramp rates increased the MHD activity, causing greater flux consumption. After the period of tearing instability, sawtooth relaxations appeared on the soft x-ray emission along central chords and the plasmas became otherwise quiescent unless limits in density or the safety factor, q, were encountered.

The operational density limit with deuterium gas puffing was investigated as a function of plasma current and toroidal field. The approach to the limit was manifested by the appearance of slowly growing, rotating MHD instabilities which eventually locked, followed by a series of global reconnection events and termination of the plasma current. The highest line-average density was $2.7 \times 10^{19} \mathrm{~m}^{-3}$. Over the current range $0.3-0.6 \mathrm{MA}$, the density 
reached with gas fueling was about $60 \%$ of the Greenwald limit [7]. During this first phase of operation, the copper stabilizer plates close to the plasma boundary were only partially covered by graphite tiles. As a result, copper was a significant impurity and this may have reduced the density limit. The copper surfaces will be entirely covered in future operation.

The operational q-limit was studied by decreasing the toroidal field during the approach of the plasma current to its maximum. As the q-limit was approached, large distortions of the plasma surface became apparent on the TV image and the soft x-ray data showed the growth of large perturbations with poloidal and toroidal mode numbers $\mathrm{m} / \mathrm{n}=2 / 1$ respectively. This occurred as the radius of the $\mathrm{q}=2$ surface from the EFIT analysis approached within about $0.1 \mathrm{~m}$ of the plasma boundary. The growth of the mode was followed by termination of the plasma current. The highest average rate of decay of the plasma current observed so far is $0.12 \mathrm{MA} / \mathrm{s}$, less than in comparable higher aspect-ratio tokamaks. Plasmas with $\mathrm{q}_{95}$, the value of $\mathrm{q}$ at the surface with $95 \%$ of the poloidal flux at the boundary, of 2.6 have been produced; the equivalent cylindrical $\mathrm{q}, \mathrm{q}_{\mathrm{cyl}}=5 \mathrm{a}^{2} \mathrm{~B}_{\mathrm{T}}\left(1+\kappa^{2}\right) / 2 \mathrm{RI}$, was as low as 1.3 . The toroidal plasma current slightly exceeded the total poloidal (or threading) current of the toroidal field coil transiently in some plasmas with the toroidal field ramp-down.

The energy confinement time in the ohmically heated plasmas has been estimated from the EFIT magnetic analysis to be in the range $15-25 \mathrm{~ms}$, although this could not be independently confirmed because measurements of the density and temperature profiles were not available. In general, the confinement time increased with plasma density and current. The values were consistent with estimates based on tokamak scalings [8] for ohmic confinement. The plasma energy reached $48 \pm 10 \mathrm{~kJ}$, corresponding to a toroidal beta $\beta_{\mathrm{T}}$ of $8.6 \pm 1.8 \%$, defined with respect to the vacuum field at the plasma geometric center.

Using initially only 8 of the 12 coupler elements, up to $1 \mathrm{MW}$ of HHFW heating power was coupled to the plasma for $50 \mathrm{~ms}$ during the current flattop phase, and up to $2 \mathrm{MW}$ was coupled briefly [9]. Based on density profiles near the edge of the plasma measured with a frequency-scanning reflectometer, the coupling resistance of the RF waves has been calculated and found to be in approximate agreement with the measurements. The successive coupler elements were operated in either a $0-\pi-0-\pi$ or a $0-\pi-\pi-0$ phasing, corresponding to toroidal wave-numbers $\mathrm{k}_{\mathrm{tor}} \approx 13 \mathrm{~m}^{-1}$ (lower phase velocity) and $\mathrm{k}_{\mathrm{tor}} \approx 9 \mathrm{~m}^{-1}$ (higher phase velocity), respectively. The RF frequency of $30 \mathrm{MHz}$ is typically $10-15$ times the fundamental cyclotron frequency in the core of NSTX plasmas. Under these conditions, the RF waves are expected to couple mainly to the electrons. The magnetic analysis showed small increases in the stored energy during the RF pulse for the higher $\mathrm{k}_{\text {tor }}$ phasing. Corresponding indications of electron heating in the plasma core have been observed on filtered x-ray detectors. Analysis of this data is complicated by metal line emission, but modeling suggests an electron temperature rise from 0.8 to $1.2 \mathrm{keV}$ early in the RF pulse. The heating was not observed for the lower $\mathrm{k}_{\mathrm{tor}}$ phasing.

Coaxial Helicity Injection (CHI) involves creating a discharge between the inner and outer lower divertor plates which are insulated from each other by ceramic breaks in the vacuum vessel. The discharge is produced in deuterium at a pressure typically $0.25-1 \mathrm{~Pa}$ by a pulsed supply capable of $1 \mathrm{kV}$ and $25 \mathrm{kA}$. The polarity of the electrodes is chosen so that, in the presence of a toroidal field, and an appropriate poloidal field, the $\mathbf{J} \times \mathbf{B}$ force is directed into the plasma chamber. To reach an approximately force-free equilibrium on the open field lines, a strong toroidal current develops in the discharge. Experiments [10] have shown that by a process of magnetic reconnection, some of this toroidal current can be transferred onto closed magnetic surfaces. The experiments in NSTX have produced $100 \mathrm{~ms}$ 
pulses with up to $130 \mathrm{kA}$ of toroidal plasma current without magnetic induction [11], as shown in Fig. 3. The ratio of the toroidal current to the injected poloidal current was as high as 10 and scaled appropriately with the applied fields. With the diagnostics currently available, it has not yet been possible to determine from the external field and flux measurements whether any of the toroidal current is flowing on closed surfaces. However, during the interval $0.06-0.10 \mathrm{~s}$, MHD fluctuations similar to those expected to accompany the reconnection process were observed on the Mirnov coils.

\section{NSTX Status}

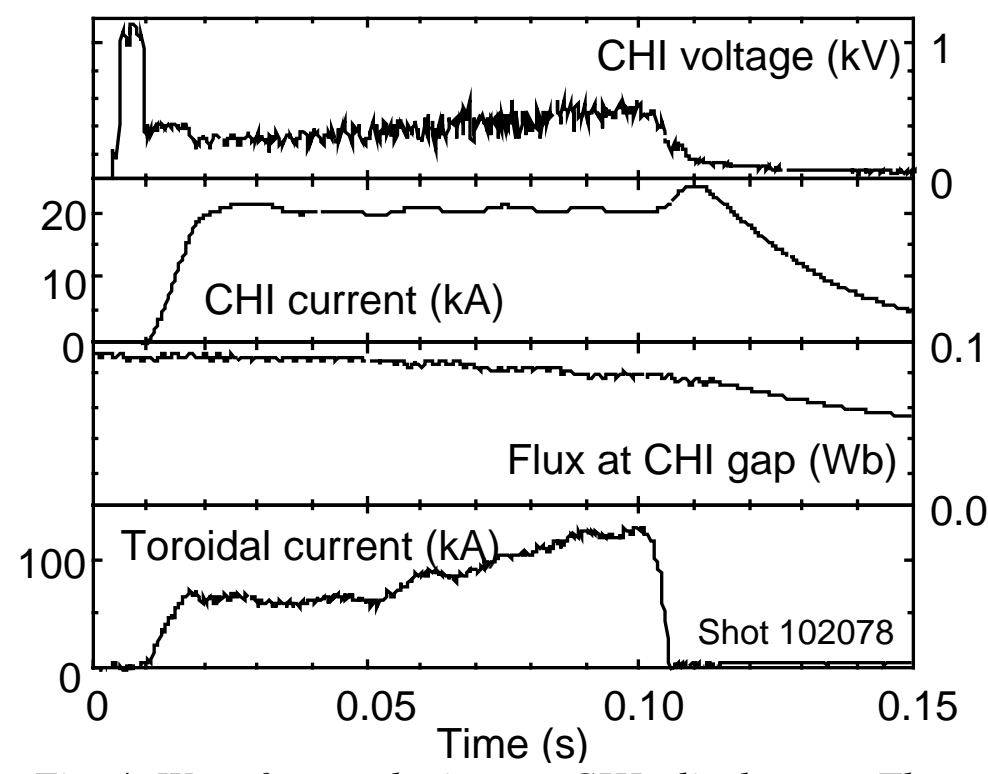

Fig. 4 Waveforms during a CHI discharge. The deuterium fill pressure was $0.4 \mathrm{~Pa}$.

The NSTX facility is currently being prepared for operation following a four-month shutdown for installation of the NBI system, final plasma-facing components, additional shielding and baffles around the CHI electrodes and new diagnostics. These include a multipulse, multi-point Thomson scattering system and additional quantitative spectroscopy for both intrinsic and NBI-excited emission. Plasma operation is scheduled to resume in July and NBI experiments to begin in October 2000.

\section{Acknowledgements}

The NSTX project is a collaboration between PPPL and 13 other institutions. Many physicists and engineers contributed to the results presented here and their efforts are gratefully acknowledged. This work is supported by U.S. DOE contract DE-AC02-76CH03073.

\section{References}

[1] J. Menard et al., Nucl. Fusion 37 (1997) 595.

[2] H. Kugel et al., Proc. 14th PSI Conf., Rosenheim, Germany, May 2000 (to appear).

[3] L.L. Lao et al., Nucl. Fusion 25 (1985) 1611.

[4] D. Gates et al., these proceedings.

[5] J. Menard et al., these proceedings.

[6] S.M. Kaye et al., these proceedings.

[7] M. Greenwald et al., Nucl. Fusion 28 (1988) 2199.

[8] S.A. Sabbagh et al., these proceedings

[9] D.W. Swain et al., these proceedings.

[10] T. Jarboe et al., Phys. Plasmas 5 (1998) 1807.

[11] R. Raman et al., these proceedings. 
The Princeton Plasma Physics Laboratory is operated by Princeton University under contract with the U.S. Department of Energy.

\author{
Information Services \\ Princeton Plasma Physics Laboratory \\ P.O. Box 451 \\ Princeton, NJ 08543
}

Phone: 609-243-2750

Fax: 609-243-2751

e-mail: pppl_info@pppl.gov

Internet Address: http://www.pppl.gov 